\title{
Research on the Effect of Business Management Training on Improving the Level of Enterprise Management
}

\author{
Long Han*, Fuquan Qin, Yiting Lu, Shuangbing Cheng, Xiaofang Zhang \\ School of Management, Qufu Normal University, Rizhao 271827, China \\ Email: qfnuhl1145@163.com
}

\begin{abstract}
The current enterprise management innovation involves many aspects, presenting a hundred bloom. By analyzing the latest articles on enterprise management innovation in domestic core journals, this paper summarizes the six research perspectives based on model system, risk management, knowledge management, process mechanism, performance mechanism and adaptation mechanism. The research perspectives are enterprise performance improvement and enterprise management innovation process. Finally, the research trend of enterprise management innovation is expected.

Keywords: enterprise management, management innovation, research review, performance improvement, adaptation mechanism
\end{abstract}

\section{Introduction}

With the continuous development of the times, if the current Chinese enterprises want to better develop, they must carry out enterprise management innovation, the more effective allocation of resources, to maximize the enterprise profits. At present, management innovation involves all aspects of the enterprise, including corporate culture, core technology, management philosophy, organizational strategy and enterprise system. In general, scholars include two types of enterprise management innovation: one is to study a specific management innovation function, and divide this specific management innovation function into strategic management innovation, supply chain management innovation and business process restructuring; the other is to explore the laws and commonalities of various management innovation.

\section{Research ideas and main perspectives of enterprise management innovation in} China

Combined with enterprise management innovation research theme keywords present network diagram, using content analysis method, the theme, basic view of combing and analysis: the discovery of enterprise management innovation research perspective is mainly divided into six aspects, including management innovation mechanism, mode, risk management, knowledge management, process mechanism, performance mechanism and adaptation mechanism. The number of the distribution of literature from different research perspectives is shown in Figure 1. In the literature from different research perspectives, the number of literature based on performance management is too large.

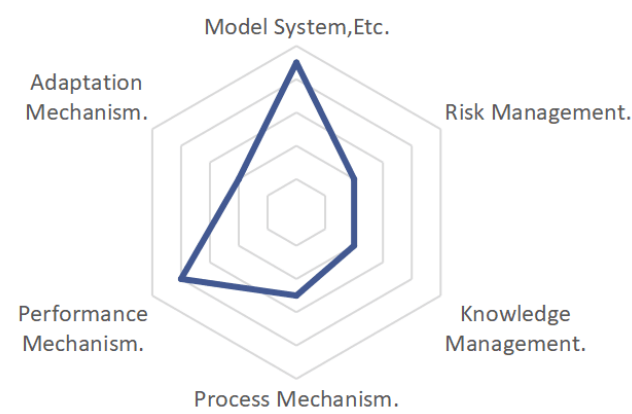

Figure 1. The number distribution of enterprise technology innovation management literature from different research perspectives.

\subsection{Based on system, mechanism and mode}

In the fierce market competition, if the start-ups want to break the monopoly of the in-position enterprises, occupy a place in the market and establish competitive advantages, they often need to adopt a certain innovation model. On the one hand, scholars' research on the enterprise management innovation system and mechanism mainly focuses on how to build 
an enterprise management innovation system and mechanism, and then improve the level of enterprise management. For example, Zhang Lu et al. ${ }^{[1]}$ (2014) is based on the root theory, Using the method of VAI to construct the evaluation model of manufacturing enterprise management innovation method selection;Guo Wei (2019) studied the innovation mode of enterprise information management under the "Internet + " environment, and integrated new thinking such as knowledge management and value chain management into the new mode of enterprise information management. In short, the research of enterprise management innovation based on system, mechanism and mode is generally the problem of how to build, or how to build enterprise innovation management mode and mechanism under different factors and in different industries.

\subsection{Based on risk management}

When undertaking management innovation, enterprises always face the various risks brought by enterprise innovation ${ }^{[2]}$. Especially in the case of limited resources and ability, enterprise management innovation risks mainly highlight the research on the identification and prevention of enterprise risks. Risk-based management innovation research, on the one hand, identified the risks in the process of enterprise technology management innovation. Gao Xinxin (2014) applied the risk matrix to each management stage of risk management, identified the enterprise technology management innovation risk; Luo Xiaofang (2015) used the improved FMEA method to identify the risks in the technology innovation process, and found that the improved FMEA method was used for the enterprise wind insurance management can not only reduce resource waste, but also improve the technology innovation of the enterprise risk management ability. On the other hand, it is to prevent risks in enterprise management innovation. Zhang Junjie and Yang Li (2015) formulated and implemented datadriven enterprise crisis management strategies by collecting, screening, tracking and analyzing enterprise crisis-related data; Ma Zesheng (2018) integrated detailed business processes, highlighting the importance of enterprise risk management for resource adjustment.

\subsection{Knowledge-based management}

The research on technology innovation management based on knowledge management mainly includes: First, emphasizing the importance of knowledge management to enterprise management innovation. For example, Li Cui and Zhang Guangtao (2016) believe that enterprise management knowledge is the core element of enterprise strategy, and believe that paying great importance to enterprise management knowledge can ensure the leadership position in fierce competition; Shen $\mathrm{He}^{[3]}(2018)$ through a questionnaire of 189 small and micro technology enterprises in Guangdong Province, found that acquired learning is affecting the introduction of technology small and micro enterprise management innovation. Second, to study the role of knowledge management on the innovation performance of enterprises. For example, Liu Libo and Shen Yuzhi (2015) studies showed that the four process dimensions of knowledge management have positive effects on management innovation performance; Wang Xin and Xu Ming (2018) studies found that knowledge management is the intermediary factor that affects the soft environment of enterprise innovation organizations on innovation performance.

\subsection{Based on the process mechanism}

Enterprise management innovation often experiences a long, tortuous and complicated reform process. Therefore, the research based on the process mechanism is still an important perspective of enterprise management innovation research in China. Scholars have divided different periods and stages according to the characteristics of enterprise management process, such as Zhou Zhonglin and Xiao Yiping ${ }^{[4]}(2015)$ focus on finding the innovation breakthrough in enterprise production management from the initial implementation, application, integration and collaborative stage; Qi Chunwei (2016) believes that small and medium-sized enterprises should implement management innovation in three stages: startup, growth period, management technology and corporate culture; Li Haijun (2018) analyzed the process of Haier enterprise reconstruction, from theoretical innovation to practical innovation, forming the current management model of Haier system.

\subsection{Based on the performance mechanism}

The research on enterprise management innovation based on performance mechanism is mainly the direct or indirect improvement of enterprise performance in the process of enterprise management innovation ${ }^{[5]}$. Scholars' studies on the direct performance of enterprise management innovation include: Yu Chuanpeng et al (2015) and Gao Pengbin (2017) through empirical research showed that enterprise management innovation has a positive impact on enterprise innovation performance; Zhang Zhengang et al (2018) found that the implementation of SME management innovation has a significant "U" -type impact on growth performance. Chen Guoqing and Li Xiaoyu (2019) studied the domestic listed automobile manufacturers implementing lean production management that there is a significant U" -type relationship between lean inventory management and enterprise performance, that is, there is the best lean inventory balance point. Studies on the indirect performance of enterprise management innovation include: Su Center (2014) has studied the impact of management 
innovation and technological innovation on enterprise performance in poor competitive environments. Discover that management innovation and technological innovation have a positive impact on improving enterprise performance. And the former has a greater impact; Xiang Sheng et al. (2015) found through the study of enterprises in Zhejiang Province, Inspired by the Government Quality Award. Many enterprises attach importance to management innovation construction and implement the excellent performance model.

\subsection{Based on the adaptation mechanism}

Adaptation mechanism mainly considers the dynamic matching relationship between enterprise management innovation and organizational elements, and highlights the synergy between enterprise internal and external environment, organizational resources, technological innovation and other organizational elements and management innovation. For example, Li Jing ${ }^{[6]}$ (2014) Based on the perspective of an integrated system, And combined with the internal situation and external development environment of the western resource-based enterprises, Analyze the integration mechanism of enterprise management innovation, Finally, we put forward the enterprise management innovation and optimization path; Yang Jiehui et al (2015) built a sustainable supply chain sustainable innovation system consisting of innovation management, environmental management and supply chain management, Atended to provide a practical path for sustainable development; Lin Yajun and Lang Yongjian (2016) put forward a dynamic real-time matching model for the triangular activation of the enterprise brand, Extract representative behavior patterns from big data, Promote enterprises to continue to innovate management models; Li Chunling and Wang Wenjun (2017) combine the internal and external development environment of wholesale and retail enterprises, develop short-term, medium-term, and long-term development management strategies for enterprises. Then continue to optimize the process of enterprise operation and capital management.

\section{Concluding remarks}

There are still many studies on the performance of corporate management innovation, and scholars have always conducted research on the performance of corporate management innovation. This is because corporate performance plays a major role in corporate development. Improving corporate performance can greatly reduce corporate operating costs, enhance corporate vitality, and enhance corporate core competitiveness. Although scholars have conducted a lot of research in the field of business management innovation in recent years, through the analysis of the literature, it is found that there are few empirical studies on business management innovation. Many documents are qualitative analysis and case analysis, and the process of mathematical modeling and data analysis. There is less quantitative analysis.

\section{References}

[1] Li Cui, Zhang Guangtao. Management innovation helps the development of enterprises "ride the boat against the current"[J]. People's Forum, 2016 (30)

[2] Feng Hailong. Definition comparison, measurement review and scale development of corporate strategic change [J]. Chinese Journal of Management, 2010, 7 (4)

[3] Zhu Qinghua, Dou Yijie. Green supply chain management game model based on government subsidy analysis [J]. Journal of Management Science, 2011, 14 (6)

[4] Zhu Qinghua, Tian Yihui. Research on the Dynamic Model of Enterprises Implementing Green Supply Chain Management [J]. Chinese Journal of Management, 2010, 7(5)

[5] Jia Guozhu, Cheng Yang. Research on the incentive and restraint mechanism of business process reengineering based on principal-agent theory [J]. Chinese Journal of Management, 2010, 7 (3)

[6] Pan Fei, Wen Donghua, Hu Qiaoyun. Total quality management strategy, environmental uncertainty and corporate performance [J]. Contemporary Finance, 2009 (1) 